\title{
Research on the Impact of Japanese Culture on China
}

\author{
Xiaojiao Li \\ School of Foreign Studies, Xi’an University, Xi’an, Shaanxi, 710065
}

Keywords: Impact, Japanese Culture, China

\begin{abstract}
Based on the perspective of media sociology, this paper analyzes the positive and negative effects of Japanese culture on the socialization of adolescents in China and puts forward some suggestions on how to deal with the negative impact of Japanese culture.
\end{abstract}

\section{Introduction}

2011 during the "May Day" period, the famous Japanese AV actress Aoi came to China to participate in the 2011 Central (Nanchang) International Automobile Festival, her arrival caused fans crazy chase. Although Aoi is a Japanese actress, it is quite influential in China [1]. A survey of "Chinese anime favorite animation works" shows that $60 \%$ of Chinese teenagers like Japanese anime, 29\% like European and American anime, and only 11\% like Chinese anime [2]. From this news and a set of figures, we can look into the issue and the extent to which Japanese culture has had an impact on the socialization of adolescents in China is unusual.

\section{The Positive Influence of Japanese Culture on the Socialization of Chinese Adolescents}

The meaning of Japanese culture is very broad. The Japanese culture referred to in this paper mainly refers to the Japanese culture that has a far-reaching impact on young people in China, that is, Japanese animation and game culture, film and music culture, fashion trends and food culture. This article examines how these Japanese cultures influence the values, worldviews, and norms of behavior for young people in China.

According to the sociologist Zheng Hangsheng's point of view, socialization refers to the individual in the process of social interaction and gradually develop a unique personality and personality, from a biological person into a social person, and through the social and cultural internalization and role knowledge learning, gradually adapt to the social life process [3]. First of all, as Japan's popular mass culture widely circulated in China, its positive significance to the socialization of Chinese adolescents can not be ignored. Its positive social impact such as social integration and orientation functions should be respected and stand by. In the following, we take Japanese animation culture as an example to briefly analyze the positive influence of Japanese culture on the socialization of Chinese adolescents. In Japan, the animation industry, the automotive industry and the digital media industry are collectively referred to as the three major economic pillar industries. Therefore, Japan is also known as the nation of comic books. Statistics show that $60 \%$ of the world's animated shows are from Japan [4]. In 2003, the total size of the world animation market was 200 billion yen, while that of Japanese animation reached 65\% [5]. At first glance, Japan's manga works really play an exemplary role in the immature domestic animation industry. The dazzling animation works also enrich the extra-curricular life of Chinese youth. Watched Japanese animation viewers can easily find that Japanese comics not only have strong national characteristics, innovative intention, cleverly conceived, humorous aesthetic, but also close to the psychological pursuit of young idols idol, and even in some ways fashion pioneer. As a result, the animation industry is not only popular, but also promotes its own national image and ideology. Most importantly, the popularity of these Japanese cultures to China is undoubtedly due to their innovation and interest. This method provides a useful reference to the making and dissemination of Chinese culture, that is, to entertain the audience in the form of entertainment, which is superior to the simple and crude theory of preaching, the former is better. Furthermore, Japanese orthodox 
films contain many places worthy of our study. For example, the Japanese people respect elders, attach great importance to etiquette, and explore the meaning of life, they all play an active social orientation function. In addition, Japan's culture such as music and costumes also functions as a cultural symbol for socially coordinated social integration. It not only meets the cultural needs of adolescents, but also establishes a concept of life that is roughly converged among adolescents, and this understanding of adolescents in China Community, to establish a sense of community identity has a positive meaning.

\section{Negative Impact of Japanese Culture}

The famous communication researcher Gerberner believes that the "symbolic reality" suggested by the mass media in modern society exerts a tremendous influence on people's understanding and understanding of the real world. Due to the propensity of the media, there is a great deviation between the "subjective reality" people portray in their minds and the objective reality that actually exists. At the same time, this kind of influence is not a short-term one, but a long-term subtle cultivation process, which unconsciously restricts people's reality view. The influence of a piece of cultural work on a person is often subtle, implicit, and long-term. Well, the question comes out: if children watch positive, fun and healthy cultural works, if children are exposed to content that is not in line with their age at a very young age, the growth caused by the adverse effects of it? Unfortunately, there are numerous such works in Japanese cultural works and animation. It is inconceivable that an unreasonably crayon-colored crayon will be sought after by children. In Naruto, the brutal boy who chooses revenge for revenge will be regarded as a symbol of cool man. His cruel, bloodthirsty Bloodthirsty personality was actually talked about. Do Chinese teenagers have their own psychological bottom line while watching these comic books and are they not discriminating right and wrong? What's more, comic artists in Japan are often beyond the scope of the original intention of creating cartoons, and their general direction is fully acknowledged. However, the content of sexual violence that appears from time to time tends to be more concealed and easily accepted by young people, so that young Chinese do not know unconsciously be "Japanese".

This form of culture is not groundless in Japanese traditional culture. In the long history of Japan, people can do whatever they want within the government's permission and control. There, men play dresses, male prostitutes, prostitutes, woodblock painters can all supernatural powers. No matter how the times change, the fundamental changes of this culture are very small and are still energetic. In Japan's modern social life, mass publications featuring nude girls are readily available. Rape and abusive shots abound on television, people are not ashamed, and it is not surprising that sexual interest seems to be a life The mainstream, for more people to accept, not as shy as the Chinese people answer [6]. However, as an ancient civilized country, can our young people accept Japan's "open-ended" culture can really leave it?

In addition to the above-mentioned reverse culture of the socialization of Chinese adolescents by Japanese culture, another thing that warrants our vigilance is the stigmatization of Japanese traditional culture. In 2006, a well-known Japanese game gave Lin Daiyu's heroine, "Dream of Red Mansions," one of the four famous Chinese portraits, actually an illegitimate daughter. In fact, in Japan, there have been many spoofs of classical Chinese classics since the beginning of 2006. In the Journey to the West, which was taken by Japan without permission, the monk not only transformed himself into a woman, but also spoke of her love for justice. "There have also been several spoof versions in Japan that are quite different from the original ones. Today, "Dream of Red Mansions" once again brutally poisoned, became a network abnormal pornography game. As a treasure of Chinese literature, Dream of Red Mansions, Romance of the Three Kingdoms, Journey to The West, Outlaws of the Marsh are known as the four masterpieces in China and are the essence of Chinese traditional culture. They also have special cultural status in China. However, Japan has flagrantly made such acts of insulting Chinese culture, leaving people feeling out of anger. Moreover, some young Chinese people who do not understand their own history and traditional culture, once exposed to this serious misrepresentation of the game, will have their negative influence rooted in 
the thinking of young people and have far-reaching consequences. This cultural invasion has resulted in Bad influence will be more difficult to eradicate and prevent than force aggression. Not only that, Japan's animation, film, music, costumes and other cultural, but also to varying degrees, learn from or even plagiarism of the essence of Chinese traditional culture. For example, the well-known Buddhism, Confucianism and Confucianism are actually introduced from China. However, many Japanese cultural works have adapted these things into their own cultural system and advertised. Such cultural practices as cultural invasions It is bound to have adverse effects on our young people.

\section{Resist Japan's Negative Culture}

In that case, how should we resist the impact of Japanese culture on young people in China? In my opinion, there are two solutions to this problem: regulation and introspection. The so-called norms and introspection, that is, from the input to regulate the import of Japanese culture, rectify all kinds of unpleasant Japanese culture and the arts filled the country; from introspection find their own deficiencies, realistic and innovative. And relative to the norms, introspection should be remembered as people always remember the rules, we should remember: only our own culture is really powerful, really attractive, really good to get rid of bad, all ages, we Only in this way can our teenagers fall in love with their own culture. Why is it that our domestic-made cultural works are not very successful in Japan? On the one hand, most domestic cultural works are cursory and over-explorative while the quality is low. On the other hand, because of the rich and colorful Japanese culture and high quality, they can meet the needs of the national spiritual culture. Therefore, it is the most important task how to develop the excellent culture that belongs to our own. In addition, in the art of film and television, we should adopt a peaceful attitude. Blind pursuit of large production, high input and surface publicity, and can not really enhance our cultural competitiveness, on the contrary, the content is the life of cultural products. Takeshi Kitano's "fireworks" and Kurosawa's "Rashomon" do not win with visual effects or propaganda, but ideological first. Even though Spielberg destroyed a real plane when he made "World War", do not forget how much he cost to get started. Therefore, China's television art creators should be patient, perseverant, perseverant, dare to express and be good at expressing themselves.

Increase the monitoring of the spread of Internet culture, Japan's AV movies and other pornographic images banned according to law. Fourth, the state should step up supervision over pirated Japanese cultural works and eliminate the large number of CD-ROM products such as pirated animation games and movies currently circulating in the market. Fifth, improve the social status of cultural creators, do not discriminate against freelancers, and improve laws and regulations to protect original works and strengthen copyright protection. Sixth, China should expand the industrial chain of the animation industry and the movie industry. For example, we can divide the animation market into different levels: one is the broadcast market of the animation itself; the other is the market of cartoon books and audiovisual products; the other is the derivative of the animation image Products, including clothing, toys, drinks, daily necessities and so on. This will not only deepen our understanding and support for our own cultural products among our young people, but also provide greater financial support to those engaged in creation and promote the reproduction of productive forces so as to form a virtuous circle. Seventhly, to properly allocate the proportions of the cultural exchanges among all countries in the society, we should ensure that our national culture will excel and at the same time avoid the monolithic phenomenon of other countries' cultures. We should introduce more excellent cultural achievements of different countries more rationally and broadcast them on a limited time basis. We should not create the illusion that a certain country's culture is superior to the culture of a certain country and mislead the youth group.

\section{Conclusion}

Japanese culture is a huge concept, and this article only explores popular culture and popular culture that have a profound impact on Chinese people, especially Chinese youths. In short, 
everyone has their own views on culture. However, we should let our young people love the culture of our own country and embrace the excellent culture of our nation rather than blindly worship Japanese culture. Therefore, from its own perspective, it is our ultimate goal to resist the erosion of Japan's unhealthy cultures by choosing a suitable cultural carrier, finding a reasonable route for cultural transmission and creating a new era culture loved by the people.

\section{References}

[1] Li Dejun. On China's Response to the U.S. Cultural Exchange with China after the Cold War [J]. Cultural Soft Power. 2017 (01)

[2] Gao Lu Yang. South Korean language and cultural promotion under the guidance of "cultural diplomacy" strategy [J]. Korea Studies Review. 2016 (02)

[3] Guo Ruijun. India's unique charm of the diplomatic form - cultural diplomacy [J]. Tangshan Vocational and Technical College 2013 (02)

[4] Xu Yanqiu. Analysis of the role of the state and China's cultural diplomacy [J]. Weifang Higher Vocational Education. 2011 (01)

[5] Guo Ruijun. India's unique charm of the diplomatic form - cultural diplomacy [J] Journal of Hunan Vocational and Technical Institute of Nationalities 2012 (03)

[6] Yan Yuan Gong, Huang Guan. Japan's popular culture diplomacy: soft power, the operation of national brands and "international cultural exchange" issue [J]. International Theory. 2017 (06) 